\title{
Comentário XI
}

\author{
Solange Ferraz de Lima \\ Vânia Carneiro de Carvalho \\ Divisão de Acervo e Curadoria do \\ Museu Paulista da USP
}

As primeiras experiências com a informatização de acervos no Museu Paulista ocorreram como conseqüência do novo direcionamento dado à instituição em 1989 na gestão de Ulpiano Toledo Bezerra de Meneses (Depto. de História da FFLCH/USP). Um Plano Diretor estabelecia os parâmetros do novo perfil do museu: as atividades de pesquisa, docência e difusão deveriam, dali em diante, ser norteadas por três linhas de pesquisa definidas a partir da especificidade do acervo e do potencial de pesquisa no campo da cultura material. $\bigcirc$ Plano Diretor partia de uma noção de curadoria que tinha como foco superar as tradicionais compartimentações entre as atividades de documentação de acervos, pesquisa e difusão. Foi com essa noção solidária de curadoria que, no início da década de 1990, as equipes de pesquisadores, especialistas e técnicos do Museu Paulista concentraram seus esforços na reorganização dos acervos e na definição das bases para a criação do sistema documental da instituição'. Ou seja, a informatização dos catálogos de acervo não se deu como mera transposição dos sistemas existentes para o ambiente digital, mas implicou ampla reformulação na própria maneira de tratar física e conceitualmente sobretudo os documentos tridimensionais e iconográficos, via de regra renegados a segundo plano em virtude da prioridade dada aos documentos textuais na produção de conhecimento histórico.

No caso específico da iconografia ${ }^{2}$, a montagem de um banco de dados informatizado teve como parâmetro as experiências em desenvolvimento na França (vidéodisque) e no Canadá (CD-ROM RW e R), voltadas para as possibilidades de uso de imagens associadas aos seus dados catalográficos. No Brasil, as instituições públicas que se destacavam no cenário nacional por contarem com bases de dados informatizados no período não dispunham de tecnologia que integrasse a imagem ao catálogo eletrônico ${ }^{3}$.

Nessa ocasião, elaboramos o projeto Banco de Dados Iconográficos, dividido em quatro módulos temáticos (cartões-postais, álbuns de família,

1. A reorganização física e documental dos acervos do Museu Paulista da USP teve início em 1991 e, no que se refere ao desenvolvimento do banco de dados, os trabalhos desenvolveram-se no âmbito da Comissão de Informática composta pelos técnicos e pesquisadores dos Serviços de Objetos, de Documentação Textual e Iconografia e do recém-criado setor de Informática.

2. O sistema documental no Museu Paulista está constituído sobre um tripé tipológico: acervo de objetos, iconografia e documentos textuais. Trataremos de agora em diante do módulo iconografia, pertinente ao tema em discussão.

3. Em 1991, a Cinemateca Brasileira já tinha projetado um banco de dados sobre a filmografia brasileira, e a ex-Funarte estava elaborando um guia de acervos fotográficos nas instituições federais. Na mesma época, 
o Instituto Joaquim $\mathrm{Na}$ buco de Pesquisas Sociais, no/Recife, informatizou $70 \%$ de seu acervo fotográfico; e no Rio de Janeiro, o CPDOC (Fundação Getúlio Vargas) assim como o setor de iconografia da Biblioteca Nacional encontravam-se com projetos de informatização em fase experimental. No caso do CPDOC, o acervo iconográfico e de depoimentos está atualmente disponível na $w e b$, e a Biblioteca Nacional expandiu seu sistema para praticamente a totalidade de seus acervos.

4. Marcos Silva (módulo caricatura), Miriam Moreira Leite (módulo álbuns de família); Maria Ângela D'Incao (módulo propaganda relativa ao espaço doméstico) e Ul piano Toledo Bezerra de Meneses (módulo cartões-postais)

5. Coleções Militão Augusto de Azervedo, Orôncio Vaz Arruda, Carlos Eugênio Marcondes de Moura e Dana Merrill. caricatura e propaganda - 1890 a 1920), cujo principal objetivo era a montagem de um banco de referências iconográficas voltado para o encaminhamento de pesquisas no campo da cultura material. O banco cobriria não só a documentação iconográfica integrante do acervo do museu, mas também de outras instituições, em um esforço de sistematizar referências mais gerais. Como bem afirmou Mendes, a experiência serviu como balão de ensaio para o módulo iconográfico dos acervos do Museu Paulista. O projeto, financiado pelo CNPq, contava com seis bolsistas de iniciação científica e aperfeiçoamento integrados aos módulos temáticos, que dispunham, cada um, de um coordenador do museu e um consultor especialista na tipologia de documentos ou nos seus temas correlatos ${ }^{4}$.

Seminários internos sobre textos que discutiam o potencial das fontes iconográficas e as especificidades de sua catalogação, levantamento de acervos e formulação da ficha catalográfica e de um vocabulário controlado mobilizaram a equipe de curadoria de imagens por três anos. Optou-se pela adoção do software Foxplus que, na época, representava uma possibilidade compatível com os recursos financeiros disponíveis além de permitir a inserção de imagens, algo ainda que não fazia parte do escopo do Microisis, o soffware livre que havia delineado os bancos bibliográficos de muitas instituições nacionais. A alimentação da base contava com um manual de orientação e um vocabulário controlado cuja elaboração pautou-se nas experiências do módulo fotográfico que integrava o banco de dados do Instituto Cultural Itaú e o thesaurus de Arquitetura da FAU/USP.

Em seu projeto inicial, o sistema informatizado do Museu Paulista contava também com catálogos paralelos, relacionados com a base de dados relativa ao acervo que poderia dar conta da contextualização documental de maneira mais ampla: biografias de autores e glossário de técnicas utilizadas, por exemplo. O registro da circulação dos documentos iconográficos com referências inclusive às pesquisas acadêmicas que alimentaram, bem como opções de cruzamento de todos os campos para a recuperação da informação e a impressão de variada tipologia de relatórios completavam a interface com o consulente.

Após quase 15 anos da implementação do sistema, parte das expectativas foi alcançada: a alimentação do módulo iconografia do Sistema Documental Informatizado do Museu Paulista contabiliza hoje 27.000 fichas. No entanto, é preciso frisar que nem todas as unidades desse acervo encontramse documentadas e descritas no mesmo grau. Para as aquisições mais recentes que contaram com patrocínio foi possível executar imediatamente após a compra o projeto de tratamento físico e documental ${ }^{5}$ - a pesquisa de contexto e identificação e o processamento físico (limpeza, embalagem, acondicionamento e geração de negativo de segurança) - que garantiu um bom nível de catalogação. Porém, para muitas coleções e fundos estamos ainda em estágio de catalogação sumária, ou seja, identificação mínima tendo em vista o controle administrativo. Nesse caso, a carência de pessoal inclusive na faixa de docentes especializados em diferentes tipologias de acervo constitui a principal razão do tratamento diferenciado dos conjuntos documentais. 
Do ponto de vista das mudanças tecnológicas, o descompasso foi ainda maior. Embora o sistema tenha contado com atualizações periódicas (atualmente o software utilizado no museu é o Visual Fox 6.0, porém já existe a versão 8.0), elas exigiam tempo de programação e adaptações para a migração dos dados que dependiam exclusivamente de um único programador, Luciano Beraldo, responsável pelo projeto de informatização desde o seu início. À atividade de criação e gerenciamento do sistema somaram-se, nesse período, o aumento vertiginoso do parque informático (eram quatro microcomputadores existentes em 1992 e atualmente são 70), a implementação das inovações trazidas com a expansão da Internet e as possibilidades de servidores capazes de suportar o sistema em rede conectando todos os setores envolvidos com a catalogação de acervos. Se, por um lado, foi possível caminhar com essa face da modernização sem defasagem, por outro, fomos obrigados a assistir a uma desaceleração das atividades voltadas especificamente para a melhoria do sistema de modo a garantir a consolidação dos catálogos mencionados e uma interface para consulta mais elaborada. No momento, o projeto inicial encontrase em fase de reformulação, tendo em vista a disponibilização dos dados na web e a finalização de parte das etapas previstas no início.

Tal como apontado por Mendes, é forçoso concordar que "é o desafio administrativo o ponto de maior dificuldade de ataque", sobretudo no tocante ao número de integrantes da equipe responsável pelo gerenciamento dos acervos e à formação requerida para tal. A experiência do Museu Paulista é, infelizmente, exemplar desse desafio. Tratando-se de um museu universitário, essa formação não se restringe a um mero treino de gerenciamento de ambientes digitais, mas implica relações estreitas com a atividade de pesquisa, na qual a permanente atualização é fundamental. Essa atualização se faz por meio de leituras, discussões organizadas por seminários internos, participação em congressos e encontros que fornecem o escopo necessário às decisões que devem integrar planejamentos de médio e longo prazos. A política restritiva de recursos humanos compromete a curadoria. E nesse ponto toca-se na questão principal levantada por Mendes: "como o horizonte digital acelera essa ação 'natural' de modelagem do passado que toda coleta e organização de dados e objetos, informações e documentos implica" e a gravidade de seus desdobramentos perante as restrições por que passam os trabalhos institucionais como as apontadas. É assim que, independente do horizonte instrumental, curadores e conservadores de acervos sempre moldam um passado. $O$ ato seletivo e valorativo de colecionar funda-se na retirada do objeto de seu contexto de uso para promover a sua inserção num conjunto que adquire novas funções de caráter simbólico, social, político e, por que não, econômico. Na arena institucional, desde o momento em que são formalmente estabelecidas, as ações de coleta e organização implicam construção do documento.

Portanto, partindo dessa premissa, o ponto principal é evidenciar os critérios e o norte das escolhas que definem essa construção. Em outras palavras, tornar claro, e tão acessível quanto os próprios acervos organizados, o processo de feitura, o todo ou a articulação pretendida que dá sentido às ações sobre as 
6. Por exemplo, o filho que doa pertences ligados à vida profissional do pai ou avô, e como esse ato é indicativo da importância dispensada à filia ção paterna no sistema de valores desse indiví duo, que, de alguma maneira,é o agente para que o reconhecimento de seu ascendente ultrapasse a esfera privada e familiar para a pública (ao inte grar seus objetos e depoimento a um museu ou arquivo que o divulgará associado a uma coleção ou fundo que levará seu sobrenome)

7. A tentativa de superar a separação epistemologicamente indesejável entre sujeito e objeto, substituindo-a por uma noção sintética denomi nada condutas motoras, é sistematizada por WAR NIER, 1999a, p. 107-117, 1999b, p. 9-15. Conceito semelhante, "performance",é utilizado por Calligaris, 1998 , p. 49 e também por MENESES, 1998 , p. 96 , ao analisar a coleção de objetos como "um ato autobiográfico". unidades do conjunto preservado. O curador relaciona-se com doadores de toda sorte e variada gama de comerciantes. Da aquisição (doação ou compra) ao acondicionamento final, o processo de integração de uma unidade iconográfica envolve inúmeras relações sociais, sujeitas às subjetividades a elas inerentes. Impossível suprimir esse dado.

Tomemos aqui, a título de exemplo, a etapa inicial de entrada do acervo no museu. No momento da aquisição nasce para o curador o primeiro esboço biográfico do objeto que se tornará documento. A troca inicial documentada pelo laudo já determina o tipo de filiação da curadoria ao campo da cultura material, as informações sobre o valor e a posição da unidade material na vida do proprietário, a trajetória e, por fim, a motivação de integrá-la a um acervo institucional. A preocupação em entender a relação do proprietário com a coleção contribui para suprimir a indesejável dicotomia entre sujeito e objeto. Significa identificar possíveis correspondências entre a escala de valores daquele indivíduo e a constelação material da qual o objeto doado faz parte ${ }^{6}$, ou seja, as funções da coleção ou dos objetos suvenires (no sentido cunhado por Susan Peirce) na formação de uma identidade social e individual. Igualmente, nos casos de doações de objetos que inscrevem uma relação corporal (móveis, vestimentas e acessórios de uso pessoal), além da homologia, vale a pena investigar aspectos da motricidade envolvida nessa relação?

Simultânea à necessidade de biografar as formas de apropriação e circulação do documento é a necessidade do contato direto do pesquisador com o objeto em questão, no intuito de melhor conhecer técnicas e materiais empregados, conforme exposto por Mendes. A caracterização morfológica indica uma rota importante, mas infelizmente pouco perseguida. No caso específico da fotografia, os critérios de seleção dos documentos relevantes para a historiografia da cultura visual são outro problema a ser enfrentado. A produção fołográfica comercial - a prática dos fotógrafos não conhecidos que compõe a grande maioria das coleções particulares formadoras da narrativa familiar das camadas médias da população - impõe os desafios de recuperar contextos de consumo completamente esquecidos. A valorização do conteúdo da imagem e de sua autoria, na tentativa de dotar a fotografia da mesma importância de outras artes visuais, deslocou o interesse para longe das condições de produção e circulação maciças, lacunas que ainda estão por ser superadas.

Um bom exemplo de como caminhar nessa direção mais uma vez exige trabalho de pesquisa. Recentemente, um colecionador autorizou a reprodução de um catálogo impresso de materiais fotográficos datado de 1917. Esse catálogo traz, em suas últimas páginas, uma vasta tipologia dos papéis utilizados para o acondicionamento da fotografia - fôlderes e passe-partouts com seus nomes e relação de preços. Boa parte dessa tipologia encontra-se representada no acervo fotográfico do Museu Paulista. Tal tipo de informação abre uma importante senda para entender o universo gráfico nacional: esses papéis eram produzidos aqui? E sua ornamentação, quem eram os produtores, quais os modelos e repertórios utilizados? Mais importante ainda: com base na variação de preços, está claro que esse segundo suporte definia o preço final 
da fotografia de estúdio, resultando, portanto, em diferenciações sociais e de ocasiões. Haveria associações de tipologias ornamentais ou de papéis com ritos registrados? A formulação de questões dessa natureza integra a pesquisa no campo da cultura material, sobretudo quando nos preocupamos com aspectos da circulação no intuito de entender a fotografia não só como mensagem e signo, mas na sua dimensão de artefato. 